\title{
As Três Guerras: o esforço pela paz e a guerra às drogas no México contemporâneo
}

\section{The Three Wars: the struggle for peace and the drug war in Mexico today}

\author{
Danillo Bragança ${ }^{1}$
}

\section{Resumo}

A Guerra às Drogas, termo cunhado na década de 1970 para designar o esforço norte-americano de combate ao uso e venda de substâncias entorpecentes, completa quarenta anos. Neste espaço de tempo, a configuração que se tinha naquele contexto, se modificou. Existe tempo suficiente para se analisar os fracassos e os êxitos neste esforço, e o caso mexicano, intrinsecamente ligado a isso, é fundamental nesta discussão. Este artigo tem como objetivo principal discutir quais foram os acertos e os equívocos na chamada Guerra às Drogas, utilizando o caso do México, por onde passam 95\% dos fluxos de narcotráfico que chegam aos Estados Unidos.

Palavras-chave:narcotráfico, México,guerra às drogas.

\footnotetext{
${ }^{1}$ Doutorando em Ciência Política pela Universidade Federal Fluminense. Email: danillo.braganca@yahoo.com.br
}

Revista Cadernos de Estudos Sociais e Políticos, v. 5, n. 9, jan-junho 2016 


\begin{abstract}
The War on Drugs, a term coined in the 1970s to designate the American effort to combat the use and sale of narcotics, completes forty years. During this time, the configuration that was in that context has changed. There is sufficient time to analyze the failures and successes in this effort, and the Mexican case, inextricably linked to it is crucial in this discussion. This article aims to discuss what were the successes and the mistakes in the socalled War on Drugs, using the case of Mexico, through which95\% of drug trafficking flows that arrive in the United States.
\end{abstract}

Keywords: drug trafficking, Mexico,war on drugs. 


\section{Introdução $^{2}$}

O México é compreendido aqui como o campo de pesquisas, a bancada para que os experimentos com segurança pública, militarização das Forças Armadas, intervenção e redução de soberania, entre outros muitos fenômenos importantes das Relações Internacionais hoje possam ser avaliados. Um microcosmo de onde se podem tirar lições importantes para muitas outras nações, tanto para práticas compartilhadas de tratamento quanto para com a questão do narcotráfico.

Os cartéis no México também são algo à parte, promovendo o tema do narcotráfico até o campo das Relações Internacionais. A diversificação e aumento do volume das atividades dos grandes cartéis mexicanos estão em curva ascendente, mesmo com o relativo êxito dos últimos anos, quando os cartéis colombianos foram desmantelados, em um espetáculo bastante conhecido, e muitos dos seus chefes presos.

Este processo não desfez a rede internacionaltampouco extinguiu o comércio de drogas por toda a América Latina, com destino aos Estados Unidos. Ao contrário, produziu uma reorganização geográfica e de mercado, e este efeito, chamado de efeito balloon(Paterson e Robinson, 2002), explica a ascensão dos cartéis mexicanos. Estes se ocuparam da parte mais importante do negócio, que é a distribuição. A Colômbia ainda conduz, por conta de sua posição geográfica extremamente favorável, toneladas e toneladas de droga para o Caribe. A região também possui outra função fundamental, que é a

\footnotetext{
${ }^{2} \mathrm{O}$ tema principal deste artigo é a apresentação de parte dos resultados da pesquisa que mantenho na pós-graduação em Relações Internacionais há quatro anos, se tomados em consideração os anos do período de especialização em História das Relações Internacionais junto à Universidade do Estado do Rio de Janeiro, e os anos de mestrado, na mesma instituição. O México é o objeto principal de investigação, assim como o fenômeno do narcotráfico e da internacionalização dos cartéis mexicanos a partir da década de 1990.
}

Revista Cadernos de Estudos Sociais e Políticos, v. 5, n. 9, jan-junho 2016 
lavagem do dinheiro em paraísos fiscais como Aruba, Ilhas Turks e Caicos, entre outros.

Os cartéis mexicanos, por sua vez, aperfeiçoaram uma série de estratégias que envolvem, por exemplo, o refino. Isso aumenta a margem de lucro em porcentagens bastante relevantes de algo que já é muito lucrativo por si próprio.Dentro disso, incluem-se a logística e o frete, o que envolve diretamente a corrupção endêmica das autoridades mexicanas e norteamericanas, a produção de drogas sintéticas, como a metanfetamina, e sua entrega em solo norte-americano. A prova disso é que, mesmo com alguma redução da demanda, por exemplo, no caso da cocaína, esta redução não é tão sensível. E não tornou também menos lucrativo, mesmo que ainda mais perigoso, ter uma empresa internacional - ilegal - dentro da rede internacional de tráfico de drogas.

Isso, no entanto, tem um efeito bastante adverso: a violência. O México se encontra hoje, segundo Manaut (2014), envolvido em três guerras, três frentes de batalha que demandam dinheiro, esforço, recursos humanos, armamento, desgaste político, desgaste econômico e constrangimento internacional, e não trazem nenhum tipo de solução política razoável e permanente.

Este artigo tem a pretensão de contribuir com o debate, apresentando o conceito de "Três Guerras" (Manaut, 2014) e como ele explica a condição do México nos dias de hoje. Na primeira parte deste texto, serão dissecadas estas três fontes de conflito de baixa intensidade que estão em curso hoje. Cada uma possui uma especificidade e similaridade com outros processos, o que justifica, de muitas formas, a sua investigação e debate. Na segunda parte, de forma paralela, serão discutidos os efeitos destas guerras, como choquede 
interesses entre Estados Unidos e México e o fracasso evidente da estratégia de "Guerras às Drogas".

\section{A violência}

Antes da apresentação das chamadas Três Guerras, necessário esclarecer uma questão importante: o conceito de guerra aqui está ligado diretamente ao que se discute no campo da Filosofia e da Teoria Social, sobretudo na tradição francesa, estruturalista, e não a visão tradicional militarista da guerra. Ao reverter o postulado clausewitziano de que "a guerra não é mais do que a continuação da política por outros meios" (Clausewitz, 2004), Foucault (2005) concebe a guerra a partir da perspectiva do poder, ou seja: a guerra ainda é uma relação de forças, na medida em que se tem como função básica a manutenção da dominação social de um grupo sobre outro e a forma como isto ocorre, a partir das tecnologias de controle que são utilizadas sob o argumento da segurança.

Agamben (2015) utiliza-se desta plataforma para a continuação de sua pesquisa e observação do tema do poder na atualidade. Na condição em que se encontra hoje, muito pode ser tirado da relação entre poder, soberania e segurança, e é esta relação que importa nesta pesquisa. As categorias tradicionais de soberania, fronteira, território, pertencimento e alteridade também servem para a compreensão do tema do narcotráfico e justificam a escolha do México como espaço de análise.

Assim, enquanto tradicionalmente as teorias de poder se concentravam na discussão sobre a função do poder soberano, hoje elas tendem a se dedicar às margens desta relação. $\mathrm{O}$ exercício de poder também precisou adequar-se, sobretudo às novas definições quanto ao papel dos Estados, do mercado e dos 
indivíduos, e à maneira pela qual os fluxos internacionais de capital, ideias e pessoas se incrementaram com a internacionalização recente.

Neste sentido, diz Agamben (2004), o Estado passa a operar nestas margens, incorporando a vida como objetivo principal da ação política -daí o termofoucaultiano "biopolítica". O indivíduo, nesta condição, tem sua liberdade transformada em normalização, assim como os grupos sociais aos quais ele faz parte. $O$ Estado garante a sua existência e reforça a sua presença expandindo os sistemas penais, prisionais e policiais. Enfraquecem-se as liberdades civis em favor do controle da ameaça, que está precisamente nestas margens. Justifica-se o aumento da vigilância e da segurança por conta do medo permanente que estas ameaças representam, assim como a inflexão nas possibilidades em que o indivíduo, historicamente, defendia-se da ação do poder soberano.

Em outras palavras, as razões de Estado tradicionais são substituídas pelas razões de segurança, e as medidas excepcionais que são tomadas em favor da manutenção da ordem pelo Estado passam a ser a regra. O Estado de Exceção, como cita Agamben (2004), garante o uso de tudo que é potencialmente eficiente contra o inimigo. Ampliam-se as liberdades dos agentes de segurança e dos agentes econômicos. A democracia erode nesta condição, e os governos passam a operar fora do sistema de pesos e contrapesos em que tradicionalmente se estabeleceraminicialmente. $\mathrm{O}$ contrato social é rompido, e a política de permanente medo abrange todos os níveis sociais, justificando a proliferação da vigilância - em meio virtual e na realidade física.

A analogia que se pretende aqui é afirmar que os mesmos discursos que justificam o estabelecimento da exceção como regra no domínio do 
Estadosão utilizados como motivação para intervenções de várias naturezas no sistema internacional. Os sistemas de vigilância que são usados para monitoramento da ameaça interna também servem para os mesmos fins no que se refere ao que vem de fora.

Este pensamento é construído da seguinte maneira: Foucault(2005), ao afirmar que a "política é a continuação da guerra por outros meios", colocase como um referencial importante na confirmação de que a Guerra às Drogas é somente um engodo para uma série de mecanismos de controle social, de formação de moralidade e de segregação. Êxitos e fracassos não são necessariamente ligados a prisões ou confisco de bens, toneladas de drogas, entre outros. Ao contrário, a constatação é de que o objetivo desta Guerra às Drogas, enquanto discurso, e seu desenrolar, as chamadas "Três Guerras", são somente consequências de um processo de normalização social.

Sobre isto, diz Foucault (2005):

\begin{abstract}
Numa sociedade como a nossa, múltiplas relações de poder perpassam, caracterizam, constituem o corpo social; elas não podem dissociar-se, nem estabelecer-se, nem funcionar sem uma produção, uma acumulação, uma circulação, um funcionamento do discurso verdadeiro. Não há exercício do poder sem certa economia dos discursos de verdade que funcionam nesse poder, a partir e através dele (p. 28).
\end{abstract}

Desta forma, a violência pode ser vista não somente pela perspectiva dos cartéis mexicanos. $\mathrm{O}$ que se propõe aqui é admitir que a violênciaresultante da ação do Estadoé causada por esta concepção de exceção e ação estatal, ou seja, a ideia de que a existência destes cartéis justifica em si o aumento 
davigilância, o incremento no controle e no militarista, e acima de tudo, o esgarçamento das relações sociais e internacionais.

É preciso, portanto, pensar as relações de poder e a forma como se materializam para além da perspectiva tradicional. O objetivo aqui é tratar estas relações como fruto das interações entre os vários atores em uma rede que funciona à margem do Estado, da soberania jurídica e do aparato institucional. O poder, nesta perspectiva, não é uma instituição, uma estrutura, mas um instrumento - discursivo - que serve para um propósito bastante específico (Rodrigues, 2013). Desta forma, mais do que falar em um antagonismo entre os atores tradicionais envolvidos, deve-se pensar de que forma uma relação de poder se constrói, envolvendo outros participantes. Não é antagonismo, porque este define a necessidade da pacificação ou da destruição, mas, ao contrário, a agonística, que se formaliza como a relação de poder, o combate, a compreensão destas relações através da luta e do conflito, da economia racional da violência.

Assim, o poder se exerce, não é. É o exercício constante do poder através da luta, do conflito, da violência, o que garante o discurso predominante. É uma disputa, portanto, de discursos, de práticas de poder. Estas são tratadas dentro de limites claros, entre as regras do poder tradicional, formalmente organizadas, e a construção dos efeitos de verdade que este poder produz. A construção do discurso moralizante, estatal e proibitivo que é o fundamento básico da "Guerra às Drogas", é justificada, por um lado, pelo exercício da soberania jurídica do Estado mexicano, mas também pela construção da verdade como discurso de poder. Internamente, sustenta as ações que o Estado mexicano desenvolve e as legitima. Externamente, garante uma série de constrangimentos ao país, além de pressões de muitas naturezas. 
Como o poder é algo transitório, relacional, volátil, é preciso que os vários discursos antagônicos sejam controlados. Estes discursos muitas vezes oferecem coerência e capacidade explicativa, apresentando novas alternativas ao discurso tradicional (Rodrigues, 2013). Os primeiros, no plural, tendem a surgir das redes, em direção ao centro. O último, singular, é endossado pelo Estado, e a luta e o conflito têm como objetivo final soterrar, marginalizar e eliminar os primeiros.

Logo, é com a genealogia dos discursos soterrados que se pode compreender com mais clareza a profundidade do conflito mexicano. Não é observando puramente a questão das relações entre Estados e cartéis, mas de que forma os cartéis ou a própria sociedade civil, descolada de seu Estado, dão forma aos combates. É preciso rastrear que novos discursos estão sendo postos à prova, e de que forma estes influenciam o discurso central. Quebra também, neste sentido, estruturas tradicionais de separação entre ordem e anarquia, entre nacional e internacional, como querem os autores de uma verve mais pós-modernista das Relações Internacionais (Ashley, 1997; Bigo, 2012; Walker, 1993).

\section{As Três Guerras}

\subsection{Estado x Cartéis}

O que se descortina em relação ao tema das Três Guerrasestá na relação complexa entre grupos de sociedade civil organizada, Estado e cartéis narcotraficantes. Estes três agentes, cada um com sua especificidade, raio de ação e objetivos, são parte do complexo sistema social mexicano. A sua explicação como fenômeno não só local, mas também transnacional, pode 
abrir novos pontos de debate e novas melhorias em termos de eficiência para as estratégias de combate.

Esta situação poderia ser ainda mais complexa se fosse aberta para uma discussão mais aprofundada a maneira pela qual os discursos que fundamentam estes três conflitos fossem identificados na arquitetura de segurança hemisférica estadunidense, e ainda, como o discurso de "Guerra às Drogas" possibilitou que a narrativa se desenrolasse desta forma. Entretanto, o objetivo aqui é ser sintético e manter o foco no domínio interno mexicano, ainda que, dentro das categorias discutidas acima, esta divisão entre dentro e fora não seja tão mais evidente.

A primeira destas guerras envolve dois lados de uma construção de verdade que tenta se impor, no México, há mais de 100 anos (Stefanoni, 2012), desde a construção do Estado mexicano. Ela se dá entre Estado mexicano, enquanto ente permanente, e os cartéis, que muitas vezes, fazem o papel de poder de fato. Estes grupos interferem permanentemente no cotidiano de muitos povoados de forma mais acentuada que as estruturas legítimas de poder.

O objeto das primeiras legislações no México, ainda na década de 1920, é a moralização e o combate à degeneração social. O escopo principal era a construção de uma sociedade civilizada (Tagle, 1991) a partir da redução do uso de substâncias entorpecentes, o que corrobora o argumento disciplinador exposto acima. A construção desse discurso é muito clara, visandoa implantação de uma sociedade de controle, com tecnologias de repressão social e a docilização dos indivíduos através da proibição dos chamados “vícios degenerativos” (México, 1967). Esta verve proibicionista tem dupla nacionalidade, sendoestadunidense de origem. A pressão dos Estados Unidos na Liga das Nações, e depois na Organização das Nações Unidas, pela 
regulação do comércio e pela moralização, tem efeitos imediatos no México (Da Silva, 2012). O resultado disto é bastante presente até hojenas relações entre esses dois países, e é mais um indicativo da dificuldade em se restringir esta análise ao campo puramente uninacional.

De forma permanente, o discurso moralista dá lugar a um enfoque muito mais duro, tradicional, militarista, estatista, quando assim é definido pela estratégia que vem de fora.E, no processo de incorporação do tema aos assuntos de segurança nacional, a partir de Richard Nixon e os eventos em Tlateloco, isto se consolidou.O inimigo passou a ser considerado dentro da lógica de defesa no México, o que cimentou a entrada definitiva dos militares na formulação da doutrina de segurança nacional. Desde este momento, as Forças Armadas mexicanas passaram a formular a maneira pela qual os grupos subversivos seriam tratados, e como seriam combatidos. No mesmo balaio foram colocados, por exemplo, o Cartel de Sinaloa e o Exército Zapatista de Libertação Nacional (EZLN), que são diametralmente diferentes.

Este é um confronto desigual, não tradicional, que não envolve dois Estados diretamente, mas que força a cooperação entre eles. Grandes carteis tem alcance suficiente para desafiar o Estado e o fazem de forma constante. As rotas de produção e abastecimento ao mercado norte-americano permanecem a plenos vapores (Osorno e Enciso, 2011). Cartéis menores não possuem estas mesmas capabilities. Fragmentam-se por conta de disputas internas ou da ação frontal do Estado. Mas ainda assim, subsistem, enriquecem, promovem a violência e suas atividades ainda se desenvolvem sem muito controle por parte do Estado (Bartolomé, 2009). 
O resultado da incorporação do narcotráfico como tema de segurança nacional é o retorno da produção, de forma paralela, ao México (Paterson e Robinson, 2009). Os cartéis mexicanos nunca inteiramente destruídos e mantiveram parcelas relevantes do mercado.Ocuparam fatias inteiras do mercado com a redução dos cartéis colombianos, que mudaram de função para se adaptar (Cepik, 2011). No final da década de 1990 e início da década de 2000, com os governos Calderón e Fox, pode-se observar um aumento bastante agudo dos pontos de contato e das frentes de batalha entre o Estado e os cartéis, espalhando o conflito ainda mais pelo território.

A Iniciativa Mérida, como pretendia também com o Plano Colômbia, tem objetivos muito claros. Além de reforçar o discurso tradicional (Rodrigues, 2012), também consolidou, simultaneamente, o protagonismo do Estado mexicano no combate aos cartéis e a influência do discurso internacionalista/intervencionista de "Guerra às Drogas". A Iniciativa Mérida é como, diz Manaut(2014), um reaparelhamento do Estado mexicano em relação às suas capabilities, defasadas em relação aos cartéis, com investimento na melhoria dos sistemas de polícia e de inteligência, mas também de justiça penal, nas instituições estatais, entre outros.

Em suma, é neste flanco que avançam os fundamentos da sociedade de controle e da intervenção externa no México. O "Estado de Segurança" como citam autores já .o avanço do Estado de exceção agambeniano, em direção a novas formas de controle. A antecipação do medo consolida a retração dos direitos civis, o aumento do encarceramento, o maior investimento em Defesa e Segurança, a confusão proposital entre as funções constitucionais das polícias e das Forças Armadas e a involução do papel externo do México e sua quase transferência de prerrogativa para os Estados Unidos no que tange, por exemplo, a defesa de seu litoral. 


\subsection{Cartéis $\mathrm{x}$ cartéis}

A disputa pela oferta, para o maior mercado consumidor do planeta é extremamente acirrada, mas nunca se desfaz, somente se reorganiza, troca de mãos, de titulares do poder naquele momento. Esta é uma guerra que se torna muito violenta, porque não há monopólio - o que, curiosamente, neste tipo de mercado com demanda inelástica e traços de acumulação primária muito evidentes, seria mais vantajoso, de alguma forma. Aqui reside a parcela mais mercadológica destas três guerras, e que explicam de certa forma porque o tema da liberalização do consumo não é ainda uma discussão de amplo espectro no México e nos Estados Unidos, ainda que existam alguns avanços.

Neste segundo nível, os muitos cartéis disputam o controle de pontos nevrálgicos das rotas de comércio. O interesse é bastante comercial, como foi dito, e a violência é um instrumento clínico que lhe favorece. Cidades, povoados, aldeias indígenas vêm sendo arrasadas de forma muito cruel, encurralando ainda mais a população, confiscando imóveis, automóveis, impondo silêncio, toque de recolher. Isto fica mais latente em cidades de fronteira, como Nuevo Laredo, Juarez, o que estende o conflito para além das fronteiras mexicanas.

Uma questão fundamental deste nível de conflito é que ele tem como efeito não a diminuição, mas ao contrário, a multiplicação dos cartéis por todo o México. Quer dizer, cartéis como La FamiliaMichoacana, KnightsTemplars, e outros, surgiram da desarticulação de grupos maiores, o que é próprio deste tipo de atividade econômica. Outro problema é o controle praticamente total que estes grupos construíram sobre países como Honduras, El Salvador, 
Cuba, entre outros, o que estende suas operações, e evidentemente, o poderio destas organizações (Maertens e De Andres, 2009). É uma expansão diferente da ocupação político-militar que se desenvolve no México, mas ainda assim, uma ocupação.

O que isto quer dizer? Que o Estado, em sua condição tradicional, nas prerrogativas de controle de território e exercício de soberania interna e externa, é contrariado em vários momentos. Seja por mera causalidade da forma como a economia, a internet, as rotas internacionais aéreas e marítimas, entre outras coisas, acaba por fazer. Seja também por em determinadas questões que o Estado não tem interesse em preencher, ou porque não lhe convém ou porque não tem capacidade para tal. Estas brechas são inevitáveis hoje, e o Estado demonstra não ter a capacidade de controlar, o que está diretamente ligado ao fluxo internacional de bens, drogas, armas, capitais e pessoas. Seja politicamente, como se vê no primeiro caso, onde a ocupação é político-militar. Seja economicamente, como se apresenta aqui neste flanco.

A intervenção neste conflito é necessária por conta da evolução econômica aguda e transnacionalizada que estes grupos, para além do discurso social, que fica mais evidente no próximo flanco. Muitas vezes os cartéis agem como corporações monopolistas, utilizando de lógica territorialista pra aumentar exponencialmente suas operações. Neste sentido, os cartéis ainda se apegam à visão tradicional de política, onde buscam soberania, território, controle de exclusão e inclusão, justicialismo, populismo. Por este motivo, esta guerra não é travada somente pelo combate tradicional, á lógica política descrita acima. Aqui, taxas de trânsito de pessoas e produtos são cobradas, como se fossem aduaneiras nacionais. Há postos de controle em muitas estradas, passagens entre cidades.

Revista Cadernos de Estudos Sociais e Políticos, v. 5, n. 9, jan-junho 2016 
Por outro lado, são eficientes também em utilizar a tecnologia na disseminação de seus produtos, vendidos como parte de uma extensa cultura, com traços específicos, ligados aos costumes dos muitos povos tradicionais que habitam o México. A internet e o rap se juntaram à cultura da morte e da religiosidade nativa e cristã mexicana para formar os narcossantos, que são produtos comerciais como outros e que respondem a esta lógica da disputa, da ocupação cultural, da resistência aos valores externos. A cultura mexicana de raiz permanece neste flanco da guerra.

\subsection{Cartéis $x$ população civil organizada}

A terceira das Três Guerras é travada num nível relativamente novo, e é um efeito desencadeado pelas outras duas. Cria-se uma lógica entre o conflito deflagrado entre o Estado e os cartéis, entre os próprios cartéis, e que agora, neste nível, envolve a população civil organizada, que se vê, de fato, encurralada entre dois lados de uma guerra que lhe desfavorece, se arma, se defende.

Este último nível em que o conflito se expande é a configuração, também causada pela fragmentação e pela estratégia equivocada do Estado, das chamadas autodefensas, formadas pela população civil destas cidades. Nestes locais, o Estado de direito não pode alcançar, e estas cidades foram ocupadas fisicamente pelos cartéis. A população, antes ou depois de uma ocupação, se organiza em torno de uma liderança, que pode ser comunal ou individual.

Estas formações civis são bastante banais no México, e há uma semelhança bastante imediata destes grupos com a demanda por terra no país. Escalante(2009) assinala que, na formação destes grupos, influenciou a ação 
de reforma agrária do governo mexicano revolucionário, na década de 1930. Isto estimulou a ocupação do espaço, de forma a não haver territórios vazios a serem ocupados no final do século XX e início do século XXI. A terra era dividida por interferência do partido oficial, o que não teve como finalidade $o$ desenvolvimento econômico igualitário dos novos centros rurais, e que computava os problemas estruturais da corrupção, do autoritarismo e do enriquecimento ilícito. A política, neste âmbito, era feito pelos grupos comunitários criados pelo partido, através das assembléias rurais.

Esta cultura local, que segundo Escalante(2009) criou uma ampla malha de caudilhos locais, dividiu para governar estes espaços. A interferência do Estado garantia a possibilidade de estes grupos se armarem, contando por vezes, com a subversão das normas para grupos ligados ao partido dominante. Mesmo isto diz Escalante(2009), não tirou o sucesso da experiência, que durante muito tempo garantiu baixos índices de violência, algo que só vem a transformar-se com o processo de internacionalização dos cartéis neste virar de século. $\mathrm{O}$ aumento dos níveis de violência, acelerado pelo discurso e pelo recrudescimento das duas outras guerras, trouxe uma profunda mudança nas relações locais. Dentro deste nível, devem-se considerar a questão indígena, muito delicada em um país como o México, fortemente ligado ao passado grandioso das civilizações pré-espanholas A opressão com fins civilizatórios, particularmente violenta no México, pelo desenvolvimento econômico e cultural do que se tinha no território, ainda está bastante visível, na enorme desigualdade social, pobreza e miséria a que é submetido o povo mexicano. Deve-se falar na questão zapatista, no sul do México, que é também expressão deste quadro de pobreza, disputa por território e influência do pensamento de esquerda. 
O que ocorre, no entanto, é que estas autodefesas, em um sentimento muitas vezes legítimo de preservação própria, segurança e retomada dos territórios perdidos, se ocupam de espaços deixados pelos cartéis, o que é da natureza do mercado e de qualquer atividade econômica com este tipo de demanda. Ao lograr expulsar os cartéis maiores, estas autodefesas, muitas vezes, os substituem, incorporando muito de suas funções, em todos os aspectos, naquela localidade. Há uma contradição aqui, já que por conta desta regulamentação dos grupos comunitários de autogestão social, a lei incorporou esta condição, garantiu-lhes legitimidade, algo que é fundamental para o tratamento da questão indígena e da questão da terra no México. Mas a natureza do sistema é muito evidente, os fluxos, muito lucrativos (Diaz, 2014), e a oferta não diminuiu, e nem vai diminuir, de forma muito aguda.

\section{Conclusão}

Sobre tudo isto, o que é fundamental definir é que o narcotráfico é, definitivamente, um problema de Relações Internacionais, e isto pode ser visto pela origem e pela própria natureza desta atividade no México, e dos desenrolares das chamadas Três Guerras. A intensa relação que, historicamente, Estados Unidos e México possuem, toda a cultura de fronteira que se desenvolveu, tanto no campo da prática quanto no imaginário, além desta clara relação produtor-consumidor, concedem ao problema do narcotráfico em si, a legitimidade como problema de Relações Internacionais.

O próprio posicionamento do país nesta rede internacional, o de distribuidor, assim como o aumento do consumo interno e a transformação do México em um grande produtor de narcóticos, somente pode ser explicado se colocarmos 
o tema do narcotráfico e do crime transnacional organizado dentro de uma lógica internacionalista. É preciso compreender que tanto a doença quanto a cura para o problema, parte do compartilhamento de culpa, e do tratamento binacional, como será exposto a partir de agora.

A abordagem sobre a questão do narcotráfico no México deve ser feita de duas maneiras, para se avaliarem de forma teórica os resultados. A primeira refere-se ao trato do problema do narcotráfico por um viés teórico não tradicional, menos baseado em relações de poder predominantes, e em forma de compreensão também predominantes e mais interessado em levantar a consideração que os discursos, de forma geral, são construídos por interesses e lógicas muitas vezes diversas. A questão geral do narcotráfico, e mais especificamente, do caso mexicano, é tratada de forma muito simplória, pelos formuladores de política externa e política de segurança. A maior parte deles desconsidera, por exemplo, o impacto que a relação demanda-oferta tem na violência, além do fato de que o próprio combate e desmantelamento de grandes cartéis, somente produz fragmentação, não extinção do mercado. $\mathrm{O}$ problema é identificado em uma causa única, que sugere uma relação muito imediata entre causa e efeito, ainda que isto não seja empiricamente comprovável, e que talvez nem precise, porque o discurso constrói a narrativa de forma separada da própria realidade. A própria criação do termo "narcoterrorismo" dá a sensação de que há uma ligação entre grupos terroristas e grupos narcotraficantes, ou que os interesses dos dois grupos são os mesmos, e esta relação resumiria em si as atividades, as naturezas e o modus operandi destes grupos, o que de fato, não se confirma.

Assim, se observarmos os resultados de estratégia como o Plano Colômbia e a Iniciativa Mérida, veremos que estas comprimem em si esta concepção monocausal do problema. Constroem-se as estratégias de combate, a 
reformulação das Forças Armadas e das estruturas de Estado e administração pública, mas não se compreende a perspectiva econômica, nem sequer a desintegração do tecido social que tem como resultado a entrada de muitos jovens nas fileiras dos cartéis. Ou seja, a estratégia que se formula por sobre visões puramente estatais, militaristas, com um montante enorme de recursos para o combate, mas que não envolva a redução das desigualdades, o combate feroz à pobreza, tende a falhar. Cada investimento em fuzil não terá efeito se não se investir na reconstrução desse tecido social, historicamente tensionado.

Em termos de êxitos, Manaut(2014) apresenta, por exemplo, a diminuição do consumo de cocaína nos Estados Unidos. Este é um aspecto respeitável, já que denota, pela primeira vez, a diminuição de um comércio - ainda que isto seja interpretado ou como a supressão de um lado e o aumento de outro, quer dizer, a redução do consumo de cocaína é apontada como pretexto do acréscimo do uso de metanfetamina nos Estados Unidos (Freeman, 2008). Outro insucesso anexo é a diminuição do poderio dos grandes cartéis, tanto no caso colombiano, na década de 1990, quanto no momento atual, quando grandes chefes dos cartéis mexicanos estão sendo ordenadamente presos. Esta é uma bandeira dos governos Fox, Calderón, e da administração mexicana em vigor, com o presidente PeñaNieto. As prisões são, por muitas vezes, revestidas de vitórias políticas, e reforçam o discurso militarista já consolidado, mas tido como ineficaz. Porém, estas prisões não representam o suficiente em termos de redução real das atividades econômicas e logísticas dos grandes cartéis. De fato, na maior parte das vezes, isto promove conflitos internos aos cartéis, ou a reconfiguração econômica e espacial das rotas, que passam para outros cartéis, e não de forma muito pacífica quase sempre. Outra vitória que pode ser adicionada está na mudança gradual de 
pensamento que a última formulação da U.S. NationalDrugControlStrategyvem demonstrando. O futuro guarda algumas soluções que precisam ser posteriormente avaliadas. 


\section{REFERÊNCIAS BIBLIOGRÁFICAS}

ASHLEY, David. History without a subject: the postmodern condition. Boulder: WestviewPress, 1997.

BARTOLOMÉ, Mariano. "Situación del crimen organizado en América Latina”. ÁgoraInternacional, vol. 4, n 10, 2009, pp. 16-20.

BIGO, Didier. "Globalization and security".The Wiley-Blackwell Companion to Political Sociology, vol. 33, 2012, p. 204.

CASTELLANOS, Laura. "Autodefensa la expresión extrema; los frutos torcidos de la inseguridad". Mexico D. F. 2013. Disponível em:

http://biblioteca.colson.edu.mx:8082/repositorio-

digital/jspui/bitstream/2012/22987/1/Nota_Hem_10282.pdf

CEPIK, Marco Aurélio Chaves; BORBA, Pedro dos Santos de. "Crime organizado, Estado e segurança internacional”. Contexto Internacional, vol. $33, n^{\circ} 2,2011$, pp. 375-405.

CLAUSEWITZ, Carl Von. Da guerra. São Paulo: Martins Fontes, 1996.

DA SILVA, Luiza Lopes. A questão das drogas nas Relações Internacionais. Brasília: EditoraFunag, 2013.

DÍAZ, Antonio Fuentes. "Autodefensa y justicia en los márgenes del Estado".Clivajes, n 2, 2014.

ESCALANTE, Fernando. "¿ Puede México ser Colombia?". Nueva sociedad. vol. 220, 2009. pp. 84-96.

FREEMAN, Laurie. "Déjàvu. La política antidrogas en la relación MéxicoEstados Unidos." ForeignAffairsenespañol, vol. 8, nº 1, 2008, pp. 15-23.

FOUCAULT, Michel. Em defesa da sociedade. Rio de Janeiro: Martins Fontes, 2009.

MAERTENS, Francis; DE ANDRÉS, Amado Philip. "David contra Goliat:¿ Pueden México, Centroamérica y el Caribe combatir con eficacia el narcotráfico, la delincuencia organizada y el terrorismo?". FRIDE, fev. 2009, pp. 1-11. 
MANAUT, Raul Benítez. "La Guerra al narcotráfico en América Latina: victoria militar, fracaso social y político". IV Congreso Internacional de Estudios de las Américas. Rio de Janeiro. EdUERJ, 2014 (no prelo).

MÉXICO. Congreso Constituyente 1916-1917: diario de debates. Instituto Nacional de Estudios Históricos de la Revolución Mexicana, 1967.

OSORNO, Diego Enrique; ENCISO, Froylan. El Cartel de Sinaloa: una historia del uso político del narco. Debolsillo, 2011.

REUTER, Peter. "Evaluando la política de drogas de los Estados Unidos". Texto de apoio para a Primera Reunión de la Comisión Latinoamericana sobre Drogas y Democracia, Rio de Janeiro, 2008.

RODRIGUES, Thiago. Narcotráfico. Rio de Janeiro: Desatino, 2012.

"Narcotráfico e militarização nas Américas: vício de

guerra". Contexto Internacional, vol. 34, no 1, 2012b, pp. 9-41.

.. "Agonismo y genealogía: hacia una analítica de las Relaciones

Internacionales". Relaciones Internacionales: Revista Académica

Cuatrimestral de Publicación Electrónica, n² 24, 2013, pp. 89-107.

ROUDINESCO, Elisabeth. A parte obscura de nós mesmos. Rio de Janeiro: Jorge Zahar, 2008.

STEFANONI, Schievenini. "Home grown: marijuana and the origins of Mexico's war on drugs". Estudios de historia moderna y contemporánea de México 47 (2012): 224-231.

TAGLE, Fernando Tenorio. El control social de las drogas en México: una aproximación a las imágenes que han proyectado sus discursos. Instituto Nacional de las Ciências Penales, 1991.

WALKER, Robert B. J. Inside/outside: internationalrelations as politicaltheory. Cambridge: Cambridge UniversityPress, 1993. 